\title{
El Corpus Christi Novohispano de 1539. Teatralización de una derrota en tres representaciones coloniales*
}

\author{
Paula Martínez Sagredo** \\ Alberto Díaz Araya***
}

\begin{abstract}
Resumen
Tradicionalmente se ha abordado el estudio del teatro evangelizador o bien otorgando individualidad metodológica a cada una de estas representaciones, o bien analizándolas desde la perspectiva de los subgéneros teatrales. Sin embargo, una comparación de teatralizaciones que compartieron un contexto histórico determinado puede proveernos de más elementos para su análisis e interpretación. Nuestra hipótesis es que, a pesar de que la mayoría de estas representaciones tenían un argumento relativamente estructurado y tradicional, en su articulación colonial novohispana no sólo se permearon de rasgos prehispánicos e indígenas coloniales sino que también permiten relevar algunas prácticas sociales que fueron puestas en escena por los nativos y por los europeos.
\end{abstract}

Palabras clave: Teatro evangelizador, Nueva España, Colonia, Motolinía.

\section{The novo-hispanic Corpus Christi of 1539. Dramatization of a defeat in three colonial representations}

\begin{abstract}
Traditionally has been approached the study of evangelist theater or methodological giving individuality to each of these representations, or analyzed from the perspective of the subgenera theater. However, a comparison to dramatizations that shared a given historical context can provide more items for analysis and interpretation. Our hypothesis is that, although most of these representations had a relatively structured and traditional argument, in its articulation colonial New Spain not only permeated the pre-Hispanic indigenous and colonial features but also allow relieving some social practices that were staged by natives and Europeans
\end{abstract}

Keywords: Evangelist theater, New Spain, Colony, Motolinia.

Recibido: 13-08-2012 Aceptado: 27-12-2012

* Artículo resultado de los proyectos FONDECYT N 1090110 y del Proyecto de Investigación Mayor de Ciencia y Tecnología de la Universidad de Tarapacá, nº 5732 - 12. Asimismo, se agradece el apoyo del Convenio de Desempeño Universidad de Tarapacá-Mineduc.

* Doctora $\odot$ en Literatura. Universidad Autónoma, Universidad de Chile, Santiago, Chile. pmartinezsagredo@gmail.com

*** Doctor en Antropología. Universidad de Tarapacá, Departamento de Ciencias Históricas y Geográficas, Tarapacá, Chile. albertodiaz@uta.cl 
La crítica ha señalad o que los misioneros utilizaron distintas estrategias para evangelizar, una de ellas el teatro. Sin embargo, bajo la categoría de teatro evangelizador se ha agrupado una serie de representaciones que comparten el hecho de haber estado a cargo de misioneros, franciscanos mayormente para el caso novohispano (Mesoamérica), pero que en términos estructurales son de distinta naturaleza y de diferente articulación discursiva, lo que nos ha llevado a indagar sobre un tipo particular de escenificaciones -las de moros y cristianos ${ }^{1}$ - dentro de la cual se clasificaría la Conquista de Jerusalén, que se realizó en 1539 en Nueva España. De entre las distintas fuentes coloniales que se refieren a esta teatralización, la Historia de los indios de Nueva España ${ }^{2}$, de fray Toribio Benavente Motolinía es una de ellas.

El contexto de la Conquista de Jerusalén en la Historia de los indios de Nueva España está determinado por una enumeración de distintas representaciones previas que tuvieron lugar en México. Es reveladora, en este sentido, la índole de hechos referidos en el Tratado Primero dentro del cual se encuentra inserta esta representación, especialmente los capítulos que le preceden. Así, luego de haber señalado las idolatrías y dificultades a las que tuvieron que sobreponerse no sólo los frailes sino también los conquistadores, de consignar el establecimiento del primer monasterio donde se administraba el sacramento, fray Toribio se decide a relatar cómo los indígenas se fueron incorporando en el culto cristiano, destacando que "aunque los indios casi todos son pobres, los señores dan liberalmente de lo que tienen para ataviar adonde se tiene de poner el Corpus Christi, y los que no tienen entre todos lo reparten y lo buscan de su trabajo" (Tratado I, cap. XII). Luego, haciendo una gala focheriana de su escasa idoneidad etológica, procede a referir la forma en que los indígenas festejan las fiestas cristianas (Pascuas, fiesta de Reyes, Candelaria, Domingo de ramos, días de los Apóstoles, etc.):

1 También conocidas como "bailes de moros y cristianos" o "los doce pares de Francia". Generalmente se realizan durante las fiestas religiosas y cívicas comunales. Entre otras manifestaciones populares, moros y cristianos permite el resumen del ideal caballeresco, de las representaciones teatrales, de los autosacramentales, de las procesiones y del poder popular frente a un enemigo común (Cáceres, 128).

2 Nos sumamos a la larga tradición de denominar el texto de Motolinía de esta manera aunque, como lo señala Baudot, los títulos de los tres manuscritos de la obra corren por distintos senderos (Benavente, 1985: 71, 77-83). La versión de la Historia que utilizamos para este estudio es la de Joaquín García Icazbalceta, quien se basa en el manuscrito de México.

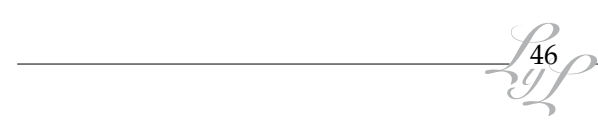


En esta casa de Tlaxcallán en el año de $1536^{3}$ vi un ofrecimiento que en ninguna otra parte de la Nueva España he visto ni creo que le hay; el cual para escribir y notar era menester otra mejor habilidad que la mía, para estimar y encarecer lo que creo que Dios tiene y estima en mucho; y fue que desde el Jueves Santo comienzan los Indios a ofrecer en la iglesia de la Madre de Dios, delante de las gradas adonde está el Santísimo Sacramento, y este día y el Viernes Santo siempre vienen ofreciendo poco a poco; pero desde el Sábado Santo a vísperas y toda la noche en peso, es tanta la gente que viene que parece que en toda la provincia no queda nadie. (Tratado I, cap. XIV 24-25)

Y desemboca, entonces, en la descripción de las fiestas de Corpus Christi y de San Juan que se celebraron en 1538 en la misma Tlaxcala. Durante la cuaresma siguiente se habría llevado a cabo la representación de la Conquista. Cabe consignar aquí que el autor de algunas de las obras de teatro evangelizador relatadas en la Historia no es otro que el mismo Motolinía. Al respecto señala Baudot (42-43) que fueron seis obras compuestas y escritas por fray Toribio para evangelizar a los indios: la Anunciación de la natividad de san Juan Bautista, la Anunciación de Nuestra Señora, la Visitación de Nuestra Señora a Santa Isabel, la Natividad de san Juan, la Caída de nuestros primeros padres -representada en náhuatl-y la Conquista de Jerusalén.

Es interesante evaluar dentro de un contexto mayor la prolífica labor teatral que llevaron a cabo los misioneros franciscanos con el fin de evangelizar a los indígenas mexicanos. La misma enumeración precedente de las obras dramáticas creadas por Motolinía son un claro ejemplo de ello. Efectivamente, no fue fray Toribio el único en explorar esta faceta dramático-evangelizadora, así como tampoco se circunscribe únicamente al siglo XVI, o a la orden franciscana, o al territorio mexicano ${ }^{4}$. Bernal Díaz del Castillo en su Historia verdadera relata cómo se llevaban a cabo representaciones de estos dramas aunque de variada envergadura:

3 La redacción de la Historia contempla un período de unos cinco años: desde 1536, en que es encargada, y 1541.

4 Véanse, por ejemplo, los casos de Guatemala con el güegüense y el de Potosí (Luis de Capoche y Arzáns de Orzúa y Vela). Matos (2008: 61) señala que encontramos representaciones de danzas de la conquista donde los protagonistas son los indígenas conquistados que combaten contra los cristianos. Los personajes que aparecen en estos dramas son destacados, como Moctezuma, Tecun Umán, Atahualpa, Cortés, Alvarado, etc. Para ejemplos en el virreinato del Perú, véase Arrom (1956: 28-35). 
Pues quiero decir el gran recaudo de canoas que teníamos ya mandado que estuviesen aparejadas y atadas de dos en dos en el gran río, junto a la villa, que pasaban de trescientas. Pues el gran recibimiento que le hicimos con arcos triunfales y con ciertas emboscadas de cristianos y moros, y otros grandes regocijos e invenciones de juegos; y le aposentamos lo mejor que pudimos, así a Cortés como a todos los que traía en su compañía, y estuvo allí seis días. (Cap. LXXXIX, énfasis nuestro)

Fray Toribio antecede la descripción de la Conquista de Jerusalen con interesantes recursos literarios:

Otra carta del mismo fraile a su prelado escribiéndole las fiestas que se hicieron en Tlaxcallán por las paces hechas entre el Emperador y el rey de Francia; el prelado se llamaba Fray Antonio de Ciudad Rodrigo. ${ }^{5}$

Como vuestra caridad sabe, las nuevas vinieron a esta tierra antes de cuaresma pocos días, y los Tlaxcaltecas quisieron primero ver lo que los Españoles y los Mexicanos hacian, y visto que hicieron y representaron la conquista de Rodas, ellos determinaron de representar la conquista de Jerusalem, el cual pronóstico cumpla Dios en nuestros días; y por la hacer más solemne acordaron de la dejar para el día de Corpus Christi, la cual fiesta regocijaron con tanto regocijo como aquí diré. (Tratado primero, cap. XV 30, el destacado es nuestro)

Esta sutil mención a la atenta revisión de la que fueron objeto los mexicas por parte de los tlaxcaltecas nos ha llevado a postular que, si bien las estructuras y argumentos de las obras que formaron parte del teatro evangelizador eran relativamente fijas y minuciosamente repasadas en las distintas etapas de la dinámica evangelizadora conventual, existió un

5 Adscribimos a la interpretación de Baudot sobre la figura de Fray Antonio en la Historia quien concluye, basándose en un fragmento anterior de la Historia, que la carta es del propio Motolinía y que habría estado dedicada a Fray Antonio, uno de los primeros doce frailes que llegaron en 1524 al Nuevo Mundo. No deja de ser curiosa la forma en la que Motolinía incorpora el relato de estas escenificaciones al referirse a las cartas que él mismo habría enviado al citado fray Antonio y citándose: "A este propósito una carta que escribió un fraile morador de Tlaxcallán a su provincial, sobre la penitencia y restituciones que hicieron los Tlaxcaltecas en la cuaresma pasada del año de 1539, y cómo celebraron la fiesta de la Anunciación y Resurrección. 'No sé con qué mejores pascuas dar a vuestra caridad, que con contarle y escribirle las buenas pascuas que Dios ha dado a éstos sus hijos los Tlaxcaltecas, y a nosotros con ellos, aunque no sé por dónde lo comience; porque es muy de sentir lo que Dios en esta gente ha obrado, que cierto mucho me han edificado en esta cuaresma, así los de la ciudad como los pueblos, hasta los Otomíes" (Tratado Primero, cap. XV p. 28). 
margen que permitió a los indígenas articular "respuestas" -fuesen éstas políticas, ideológicas, estéticas, etc.- que se manifestaron plásticamente en la puesta en escena de dichas obras.

Al respecto, el relato de Bernal Díaz nos permite imaginar más claramente este panorama al ofrecernos otro antecedente contextual mucho más próximo a nuestra Conquista, esta vez con la representación de la Conquista de Rodas, ambas escenificadas para el Corpus Christi de 1539: la de Rodas en México y la de Jerusalén en Tlaxcala. Un dato interesante lo constituye una singular puesta en escena ${ }^{6}$ que se llevó a cabo el día anterior a la Conquista de Rodas luego de un fastuoso banquete. El mismo cronista describe:

Y volviendo a nuestra fiesta, amaneció hecho un bosque en la plaza mayor de México ${ }^{7}$, con tanta diversidad de árboles, tan al natural como si allí hubieran nacido. Había en medio unos árboles como que estaban caídos de viejos y podridos, y otros llenos de moho, con unas yerbecitas que parece que nacían de ellos; y de otros árboles colgaban uno como vello, y otros de manera, tan perfectamente puesto que era cosa de notar.

Y dentro en el bosque había muchos venados, y conejos, y liebres, y zorros, y adives, y muchos géneros de alimañas chicas de las que hay en esta tierra, y dos leoncillos y cuatro tigres pequeños y teníanlos en corrales que hicieron en el mesmo bosque [...], porque encima de los árboles había tanta diversidad de aves pequeñas, de cuantas se crían en la Nueva España, que son tantas y de tantas raleas, que sería larga relación se las hobiese de contar. Y había otras arboledas muy espesas algo apartadas del bosque, y en cada una de ellas un escuadrón de salvajes con sus garrotes añudados y retuertos,

6 Dada la contigüidad de estas representaciones, Fernando Horcasitas ha considerado que esta primera escenificación -a la cual ha dado en llamar La Batalla de los salvajes- constituyó la primera parte de la Conquista de Rodas.

$7 \quad$ El recurso utilizado por el cronista para dar inicio a su relato de las teatralidades o escenificaciones consiste en obliterar todo el proceso de preparación de semejantes puestas en escena, dando la impresión de que estos mundos ficticios construidos hubiesen aparecido por arte de magia en medio de Tenochtitlan. Añadido esto a la recurrente omisión del autor no necesariamente indica que esta representación tuviese un origen prehispánico (Horcasitas, 2004: 615-616), pues es el mismo mecanismo que utiliza en la descripción de la Conquista de Rodas, cuya argumento es sin lugar a dudas producto del teatro evangelizador; así como tampoco es un indicador de ello el tema de la representación, puesto que comparte numerosos elementos con La caída de nuestros primeros padres, ocurrida en Tlaxcala en 1538. 
y otros salvajes con arcos y flechas, y vanse a la caza, porque en aquel instante las soltaron de los corrales, y corren tras de ellas por el bosque, y salen a la plaza mayor [...] Dejemos esto, que no fue nada para la invención que hubo de jinetes y de negros y negras con su rey y reina, y todos a caballo, que eran más de cincuenta, y de las grandes riquezas que traían sobre sí de oro y piedras [...] y luego van contra los salvajes, y tienen otra quistión sobre la caza, que cosa era de ver la diversidad de rostros que llevaban las máscaras que traían, y cómo las negras daban de mamar a sus negritos, y cómo hacían fiestas a la reina. (Díaz del Castillo (b) 754-755)

Parece haber una evidente diferencia entre la Batalla y ambas Conquistas, al menos en cuanto a los objetivos con que las dos últimas fueron escenificadas, los cuales fueron explícitamente señalados por Motolinía: "el cual pronóstico [la conquista] cumpla Dios en nuestros días; y por la hacer más solemne acordaron de la dejar para el día de Corpus Christi, la cual fiesta regocijaron con tanto regocijo como aquí diré" (op. cit.). Podría intentarse encontrar algunas semejanzas en este sentido entre las tres obras, sin embargo la fascinación que sintió Díaz del Castillo al ver la puesta en escena de la Batalla parece haber ido en directo desmedro de su descripción del argumento. Sólo podemos rescatar de esta última un par estructural que se repite en las Conquistas: en las tres uno de los bandos está representado por los cristianos (con personajes como los reyes, los conquistadores, etc.), evidentemente en una posición de superioridad moral con respecto al antagonista, que bien pueden ser los moros, los mismos indígenas novohispanos o los salvajes, categoría esta última que permitiría englobar a los dos primeros.

Desgraciadamente no se menciona en las fuentes qué indígenas realizaron la Batalla de los naturales, aunque se podría asumir que fueron los mismos mexicas. Sin embargo, en cuanto a la articulación del mencionado diálogo interescénico, resulta destacable que mientras Aracil propone que en estas representaciones sólo actuaban los indígenas principales y nobles, nos inclinamos a pensar -sobre la base de la comparación entre las descripciones de Motolinía, Bernal Díaz y Las Casas- que los roles protagónicos también eran representados por españoles principales, como el mismo Cortés. Así, en la Conquista de Rodas, el conquistador representó al gran capitán de Rodas (Díaz del Castillo 755), mientras que en la de Jerusalén fue Soldán de Babilonia y 
Tlatoani de Jerusalén. Para Ramírez "más que una crítica, en la base de la presentación de Cortés como un moro se encuentra un homenaje a quien no duda en identificarse con la actividad de los misioneros y, de alguna manera, con la defensa de los indígenas" (150). Volveremos más adelante con esta idea.

La escenificación de estas contiendas responde no sólo a un recurso teatral de evangelización, sino también a un mecanismo ideológico. Recordemos que la Isla de Rodas cayó en manos de los turcos en 1522 y que en 1535 Carlos V había logrado conquistar Túnez, lo que significó para los franciscanos que el imperio se aproximaba hacia Oriente Cercano.

Poco a poco irían cayendo las islas griegas, incluyendo Rodas, en manos del emperador, hasta su feliz entrada en Jerusalén, 'el cual pronóstico cumpla Dios en nuestros días'. Una vez coronado como rey de Jerusalén se iniciaría una nueva época, [...] se cristalizaría el concepto del 'imperio apocalíptico’de frailes e indios en América [...] La conquista de Rodas, y posteriormente la de Jerusalén, por tanto, no sólo simbolizarían el papel del rey de España como emperador Universal, sino que significarían la gran conquista espiritual del mundo por el cristianismo. (Horcasitas, 2004: 612)

Por lo tanto, si ni Rodas ni Jerusalén estaban en manos de los españoles, ¿por qué representarlas como ciudades conquistadas por ellos? Creemos que la respuesta la da el mismo fray Toribio al decir "el cual pronóstico cumpla Dios en nuestros días". Se trata de una intención de prefiguración ${ }^{8}$ que es utilizada no solo teniendo a un público español en vistas, sino también vinculando otro discurso conquistador para otro receptor, los indígenas. Así, jugando con un imaginario tan lejano para los americanos como Rodas y como Jerusalén ${ }^{9}$, o tan cercano como Tenochtitlán, los misioneros franciscanos dan a entender a los indígenas que su fe también sería conquistada por las huestes del cristianismo.

8 Entendemos por prefiguración un mecanismo, en este caso dramático, a través del cual la escenificación llevada a cabo representa anticipadamente una realidad que, por parte de alguno de los involucrados en la trama, se requiere concretizar.

9 Como veremos más adelante, en la Conquista de Jerusalén se crea un lazo analógico entre la ciudad de Jerusalén y la fe de los indígenas, ambas caracterizadas en términos de tierra santa. 
Podemos, en este sentido, plantear la posibilidad de hacer una lectura de las tres obras en conjunto en cuanto a la concretización de uno de los actantes: el antagonista-indígena. Si seguimos el orden secuencial de las representaciones, tenemos en primer lugar la Batalla, en donde los perseguidos, ergo el antagonista, son los naturales. Esta primera teatralización cumpliría el rol de establecer inmediatamente el vínculo entre los espectadores indígenas y los naturales de la representación. En seguida, en la Conquista de Rodas y en la de Jerusalén serán los turcos e infieles. Considerando el estrecho lapso de tiempo en que fueron representadas, la configuración del antagonista quedó fuertemente plasmada en la retina de los observadores: los infieles son los naturales o salvajes que aún no han entrado en la fe cristiana. Esta secuencia pondría en un lugar especial de interpretación a la Conquista de Jerusalén, ya que se constituiría como el punto cúlmine de este discurso.

ParaAracil, la Conquista de Jerusalén respondea una triplearticulación de la cual era objeto este método por parte de los franciscanos. Si bien su objetivo principal era atraer a los indios paganos a la fe católica, también permitió canalizar el espíritu de la cruzada medieval que aún se encontraba latente en la mentalidad de los españoles y, como lo demuestran los ejemplos vistos, un claro discurso político:

Aquel teatro representado por los indígenas en su propia lengua bajo la tutela de los frailes asumió y sintetizó los conocimientos adquiridos por los misioneros sobre la lengua y la cultura indígenas, las tradiciones dramáticas española y prehispánica y los más amplios recursos de la predicación con el fin de lograr la conversión y la educación doctrinal y moral de los naturales, pero también, al menos en el ámbito de la orden franciscana que le dio origen, de transmitir determinados planteamientos ideológico-políticos relacionados sobre todo con el problema de la conquista y su influencia en la posterior organización del poder colonial. (Aracil, 2008: 221)

Sin embargo, no sólo las discursividades europeas estaban en juego. En el contexto histórico interno, estas representaciones responden también a otro tipo de dinámicas que están marcadas por las guerras floridas entre la triple alianza (Tenochtitlán, Texcoco y Tlacopán) y Tlaxcala, cuyo objetivo era la captura de prisioneros que serían 
utilizados con fines sacrificiales por los vencedores. "El protocolo que caracterizó las guerras floridas funcionó durante el siglo XV, pero progresivamente la rivalidad entre México y Tlaxcala fue perdiendo los rasgos ceremoniales hasta convertir estas representaciones en verdaderos enfrentamientos entre el interés expansionista mexica y la resistencia tlaxcalteca" (Ramírez 153). Recordemos también que Tlaxcala fue vital en el triunfo de la empresa conquistadora de Cortés. En los primeros años de la conquista, Hernán Cortés, implacable estratega, supo utilizar las rivalidades locales existentes entre Tlaxcala y Tenochtitlán, lo que le valdría a la primera la consignación en 1535 de un escudo de armas. La alianza cortesiana-tlaxcaltecana si bien tuvo momentos de irregularidades, permitió a Tlaxcala gozar de cierta autonomía gubernamental con respecto a México.

En términos generales, la alianza se relacionó con temas militares, político-administrativos y tributarios: en lo militar supuso la colaboración de Tlaxcala con los españoles para conquistar México [...]. En lo político-administrativo, la alianza favoreció la subsistencia de cuatro señoríos indígenas, hizo de Tlaxcala un pueblo que dependía directamente del rey y fortaleció la injerencia de las casas señoriales indígenas en el control de tributos, tierras y pobladores [...] en lo tributario, permitió que los tlaxcaltecas disfrutaran de diversas modalidades para el pago de sus impuestos sin que eso redundara en una exención. (Ramírez, 2009: 153-1549)

\section{Del texto de la representación a la estructura de la conquista}

Para Arróniz uno de los antecedentes de la Conquista de Jerusalén es una pieza puesta en escena a finales del siglo XI por Godofredo, aunque Aracil considera que más bien corresponde a una actualización del tema de la conquista, "dado que el espíritu de cruzada sigue vivo en la época" ("Teatro e ideología" 41). Sin embargo, la diferencia entre estos autores se evidencia también en la clasificación tipológica que hacen de la obra en cuestión. Mientras que el primero considera que responde a la estructura de un autosacramental, la investigadora alicantina, y nosotros nos sumamos a su interpretación, la incorpora dentro de la 
tradición de "moros y cristianos"10 basándose en que el centro temático de la representación es el Bautismo (ibíd.: 42).

En términos estructurales, es posible delimitar una serie de motivos (iniciales, centrales y finales) que caracterizan estas danzas ${ }^{11}$. Dentro de la primera categoría aparecen los motivos del bien preciado (conquista del bien invalorable); el presagio y la oración; en la segunda, el llamado a la guerra (arenga a los ejércitos moros y cristianos), el reto y la embajada cristiana y la guerra; en la última, la victoria de los cristianos, el enojo del rey, la apoteosis del vencedor, la recuperación del bien preciado y el bautizo de los moros y fiesta general (Cáceres, 2005: 59-65). Evidentemente, estos motivos se reformulan y resignifican con cada puesta en escena ${ }^{12}$.

En la Conquista de Jerusalén ${ }^{13}$ los personajes pueden ser divididos en seis grupos: prelados (entre ellos el Papa), los ejércitos europeos

10 Estas representaciones tienen su origen en el siglo XI en Lérida y continúan hasta el día de hoy tanto en la Península como en América. "Si bien muchas expresiones dancísticas acompañadas de música, diálogos, etc., pudieran provenir desde el Neolítico como parte de cultos agrarios, al paso del tiempo se fueron incorporando otras expresiones que tuvieron su origen en diversos acontecimientos históricos, entre los que se encuentran las Cruzadas y los intentos por recuperar Jerusalem, o los enfrentamientos contra los moros que ocuparon más de la mitad sur de lo que hoy es España [...] Otra vertiente son los cantares de gesta como la Chanson de Roland, que escenifica los combates entre moros y cristianos que culmina con el triunfo de Carlomagno" (Matos, 2008: 61). Es necesario diferenciar entre danzas de moros y cristianos y danzas de la conquista. Mientras las danzas de moros y cristianos representan el encuentro entre moros o paganos y cristianos, las danzas de la conquista son "todas las representaciones que se adaptaron a partir de la empresa conquistadora iniciada en 1492, en la que los contendientes, de un lado y del otro, corresponden a figuras de individuos, reales o inventados, que participaron en la conquista o defensa de los diversos territorios sujetos a la corona española" (Ibídem).

11 Estas representaciones aparecen bajo una variada terminología que va desde danzas, bailes, escenificaciones, representaciones, etc.

12 Para una comparación entre los motivos peninsulares y los americanos, véase Demetrio Brisset (1993: 4-5), García-Verdugo (2008: 90-91) y sobre los ciclos de moros y cristianos véase Beutler (226228).

13 Según la descripción de fray Toribio, el escenario que fue adecuado para la Conquista fue impresionante. Señala el franciscano: "En Tlaxcallán, en la ciudad que de nuevo han comenzado a edificar, abajo en lo llano, dejaron en el medio una grande y muy gentil plaza, en la cual tenían hecha a Jerusalem encima de unas casas que hacen para el cabildo, sobre el sitio que ya los edificios iban en altura de un estado; igualáronlo todo e hinchiéronlo de tierra, e hicieron cinco torres; la una de homenaje en medio, mayor que las otras, y las cuatro a los cuatro cantos; estaban cerradas de una cerca muy almenada, y las torres también muy almenadas y galanas, de muchas ventanas y galanes arcos, todo lleno de rosas y flores. De frente de Jerusalem, a la parte oriental fuera de la plaza, estaba aposentado el Señor Emperador; a la parte diestra de Jerusalem estaba el real adonde el ejército de España se había de aposentar; al opósito estaba aparte aparejado para las provincias de la Nueva España; en el medio de la plaza estaba Santa Fe, adonde se había de aposentar el Emperador con su ejército: todos estos lugares estaban cercados y por de fuera pintados de canteado, con sus troneras, saeteras y almenas muy al natural" (Tratado primero, cap. XV 30-31). Esta descripción permite imaginar no sólo la cantidad de tiempo destinada para tal representación sino también la mano de obra. Suponemos -ya que en general las crónicas adolecen de las descripciones de estos procesos previos- que el período anterior a la escenificación se constituye como un intersticio, una previa puesta en escena, de lo que tendría lugar, probablemente, meses más tarde. 
(capitaneados por Pimentel ${ }^{14}$ ), los ejércitos americanos (capitaneados por Antonio de Mendoza y entre los cuales anecdóticamente se encuentran representados los peruanos), los ejército musulmanes (al mando de Cortés), la corte imperial y la corte celestial (santos).

Llegado el Santísimo Sacramento a la dicha plaza, con el cual iban el Papa, cardenales y obispos contrahechos, asentáronse en su cadalso, que para esto estaba aparejado y muy adornado cerca de Jerusalem, para que delante del Santísimo Sacramento pasasen todas las fiestas. Luego comenzó a entrar el ejército de España a poner cerco a Jerusalem, y pasando delante del Corpus Christi atravesaron la plaza y asentaron su real a la diestra parte. Tardó buen rato en entrar, porque eran mucha gente repartida en tres escuadrones. Iba en la vanguardia, con la bandera de las armas reales, la gente del reino de Castilla y de León, y la gente del capitán general, que era Don Antonio Pimentel conde de Benavente, con su bandera de sus armas. En la batalla iban Toledo, Aragón, Galicia, Granada, Vizcaya y Navarra. En la retaguardia iban Alemania, Roma e Italianos. Había entre todos pocas diferencias de trajes, porque como los Indios no los han visto ni lo saben, no lo usan hacer, y por esto entraron todos como Españoles soldados, con sus trompetas contrahaciendo las de España, y con sus atambores y pífanos muy ordenados; iban de cinco en cinco en hilera, a su paso de los atambores. (Tratado primero, cap. XV 31)

La toma de Jerusalén ocurre en varias batallas en las que los ejércitos español y náhuatl se enfrentan a los "moros" y "judíos" que se han apoderado de Tierra Santa. En el primer enfrentamiento vence el primer conglomerado:

En aposentándose éstos, luego salieron al campo a dar la batalla el ejército de los Españoles, los cuales en buena orden se fueron derecho a Jerusalem, y como el Soldán los vio venir, que era el marqués del Valle Don Hernando Cortés, mandó salir

14 Es interesante relacionar la dedicatoria de la Historia al conde Pimentel con el cambio de nombre del mismísimo fray Toribio cuyo primer apellido fue de Paredes. Baudot señala que era costumbre de la época entre los religiosos el tomar el apellido de la ciudad conocida más cercana del solar original. En este caso coincide además con que Benavente es el señorío del conde Pimentel. 
su gente al campo para dar la batalla; y salida, era gente bien lucida y diferenciada de toda la otra, que traían unos bonetes como usan los Moros; y tocada al arma de ambas partes, se juntaron y pelearon con mucha grita y estruendo de trompetas, tambores y pífanos, y comenzó a mostrarse la victoria por los Españoles, retrayendo a los Moros y prendiendo algunos de ellos, y quedando otros caídos, aunque ninguno herido. Acabado esto, tornose el ejército de España a recoger a su real en buen orden. Luego tornaron a tocar arma, y salieron los de la Nueva España, y luego salieron los de Jerusalem y pelearon un rato, y también vencieron y encerraron a los Moros en su ciudad, y llevaron algunos cautivos a su real, quedando otros caídos en el campo. (Tratado primero, cap. XV 31)

En el segundo asalto el ejército de los españoles y nahuas es derrotado ya que los moros reciben ayuda de "la gente de Galilea, Judea, Samaria, Damasco y de toda tierra de la Siria, con mucha provisión y munición, con lo cual los de Jerusalem se alegraron y regocijaron mucho" (ibíd.). Habiendo sido derrotados en esta batalla, don Antonio Pimentel, capitán general del ejército cristiano, envía una carta a Carlos I para que acuda en su ayuda, lo que da lugar a un tercer enfrentamiento. Hemos de señalar aquí que, por lo explicitado en las fuentes, el texto de esta Conquista de Jerusalén son precisamente estas cartas que constituyen el diálogo que da origen a las acciones y que, a la vez, recapitula lo acontecido en la escena anterior. En la carta señalada, Pimentel escribe al Emperador:

¿Será Vuestra Majestad sabedor cómo allegó el ejército aquí sobre Jerusalem, y luego asentamos real en lugar fuerte y seguro, y salimos al campo contra la ciudad, y los que dentro estaban salieron al campo, y habiendo peleado, el ejército de los Españoles, criados de Vuestra Majestad, y vuestros capitanes y soldados viejos así peleaban que parecían tigres y leones; bien se mostraron ser valientes hombres, y sobre todos pareció hacer ventaja la gente del reino de León. Pasado esto vino gran socorro de Moros y Judíos con mucha munición y bastimentos, y los de Jerusalem como se hallaron favorecidos, salieron al campo y nosotros salimos al encuentro. Verdad es que cayeron algunos de los nuestros, de la gente que no estaba muy diestra ni se había visto en campo con Moros; todos los demás están con mucho ánimo, esperando lo que Vuestra Majestad será 
servido mandar, para obedecer en todo. De Vuestra Majestad siervo y criado. -DON ANTONIO PIMENTEL. (Tratado primero, cap. XV 32)

A lo que responde el monarca:

'A mi caro y muy amado primo, Don Antonio Pimentel, capitán general del ejército de España. Vi vuestra letra, con la cual holgué en saber cuán esforzadamente lo habéis hecho. Tendréis mucho cuidado que de aquí adelante ningún socorro pueda entrar en la ciudad, y para esto pondréis todas las guardas necesarias, y hacerme heis saber si vuestro real está bien proveído; y sabed cómo he sido servido de esos caballeros, los cuales recibirán de mí muy señaladas mercedes; y encomendadme a todos esos capitanes y soldados viejos, y sea Dios en vuestra guarda.- DON CARLOS, EMPERADOR'. (Tratado primero, cap. XV 32)

Enseguida será el turno de Antonio de Mendoza, a la sazón capitán general de los tlaxcaltecas, de escribir a Carlos I, quien le responde en una misiva que es de gran interés porque, por un lado le responde a un personaje ficticio, al capitán de los indígenas, pero el vocativo que utiliza en la carta es emitido al personaje de la realidad, al verdadero virrey Mendoza, activando la constante referencia a ambos planos, ficcional y real:

'Amado pariente y mi gran capitán sobre todo el ejército de la Nueva España. Esforzaos como valiente guerrero y esforzad a todos esos caballeros y soldados; y si ha venido socorro a la ciudad, tened por cierto que de arriba del cielo vendrá nuestro favor y ayuda. En las batallas diversos son los acontecimientos, y el que hoy vence mañana es vencido, y el que fue vencido otro día es vencedor. Yo estoy determinado de luego esta noche sin dormir sueño andarla toda y amanecer sobre Jerusalem. Estaréis apercibido y puesto en orden con todo el ejército, y pues tan presto seré con vosotros, sed consolados y animados; y escribid luego al capitán general de los Españoles, para que también esté a punto con su gente, porque luego que yo llegue, cuando pensaren que llego fatigado, demos sobre ellos y cerquemos la ciudad; y Yo iré por la frontera, y vuestro ejército por la siniestra parte, y el ejército de España por la parte derecha, por manera que no se puedan escapar de nuestras 
manos. Nuestro Señor sea en vuestra guarda. -DON CARLOS, EMPERADOR'. (Tratado primero, cap. XV 32)

Enseguida interviene en escena el Emperador, el rey de Francia y el de Hungría con lo que se produce un nuevo enfrentamiento en el que vence el ejército cristiano. A continuación, Carlos I envía una carta al Papa donde, como señalamos anteriormente, recapitula lo sucedido y pide su intervención. Nos parece destacable de esta carta el siguiente fragmento en la medida en que posiciona, a través de la analogía, la fe de los indígenas como un "lugar santo".

[...] Yo al presente estoy con mucho cuidado hasta saber el suceso de mi viaje: suplico a Tu Santidad me favorezcas con oraciones y ruegues a Dios por mí y por mis ejércitos, porque Yo estoy determinado de tomar a Jerusalem y a todos los otros Lugares Santos, o morir sobre esta demanda, por lo cual humildemente te ruego que desde allá a todos nos eches tu bendición. -DON CARLOS, EMPERADOR'. (Ibíd., énfasis nuestro)

La respuesta del Papa no se hace esperar y le señala "que se hará lo que quieres, y así mando luego a mis muy amados hermanos los cardenales, y a los obispos con todos los otros prelados, órdenes de San Francisco y San Diego, y a todos los hijos de la Iglesia, que hagan sufragio; y para que esto tenga efecto, luego despacho y concedo un gran jubileo para toda la cristiandad" (Tratado primero, cap. XV 33). Enseguida todos comienzan sus oraciones y

estando todos puestos de rodillas, apareció un ángel en la esquina de su real, el cual consolándolos dijo: 'Dios ha oído vuestra oración, y le ha placido mucho vuestra determinación que tenéis de morir por su honra y servicio en la demanda de Jerusalem, porque lugar tan santo no quiere que más le posean los enemigos de la fe; y ha querido poneros en tantos trabajos para ver vuestra constancia y fortaleza: no tengáis temor que vuestros enemigos prevalezcan contra vosotros, y para más seguridad os enviará Dios a vuestro patrón el Apóstol Santiago'. Con esto quedaron todos muy consolados y comenzaron a decir, 'Santiago, Santiago, patrón de nuestra España'; en esto entró Santiago en un caballo blanco como la nieve y el mismo vestido como le suelen pintar. (Ibid. 33) 
A Santiago apóstol se unirá, luego de que en otra escaramuza los moros vencieran a los cristianos, san Hipólito el náhuatl. La figura de san Hipólito, patrono de Nueva España, es crucial para establecer el vínculo de la prefiguración entre el discurso ficcional y el real, pues fue en el día de este santo que se produce la caída de Tenochtitlán. Ya con Hipólito en el campo de batalla el pronóstico era evidente. Sin embargo, probablemente para no dejar lugar a dudas, fray Toribio añade una última figura auspiciatoria, san Miguel arcángel, quien habla a los moros en los siguientes términos:

'Si Dios mirase a vuestras maldades y pecados y no a su gran misericordia, ya os habría puesto en el profundo del infierno, y la tierra se hubiera abierto y tragadoos vivos; pero porque habéis tenido reverencia a los Lugares Santos quiere usar con vosotros su misericordia y esperaros a penitencia, si de todo corazón a él os convertís; por tanto, conoced al Señor de la Majestad, Criador de todas las cosas, y creed en su preciosísimo Hijo Jesucristo, y aplacadle con lágrimas y verdadera penitencia': y esto dicho desapareció. (Tratado primero, cap. XV 33)

Soldán, interpretado por Cortés, interpela a sus huestes para que juntos reconozcan el error en el que han estado viviendo. A través de otra misiva, Soldán se pone a las órdenes de Carlos I. Cuando éste lee la carta, se dirige a las puertas de Jerusalén donde se reúne con el tetrarca, quien es bautizado junto con todos los moros e indios que le acompañaban.

Como se puede apreciar, en el caso de la Conquista, la mayoría de los motivos comentados anteriormente se instauran diegéticamente a partir de una doble identificación simbólica. Como lo señala Toro, "en estos textos [crónicas del siglo XVI y XVII] contamos con una teatralización/ escenificación de parlamentos y acciones de los personajes que a su vez son refuncionalizados dramáticamente" (2006: 89), lo que interesa no es solo lo que se dice, sino "cómo se dice y escenifica lo dicho, lo que se configura detrás de la palabra y que revela la escenificación [...] lo significativo no es el nivel del enunciado, sino de la enunciación, no el del inventio, sino el del elocutio como se formula en la retórica antigua. Lo principal es que algo se dice/representa sin evaluar si lo dicho o representado es falso o verdadero" (2006: 92). 
El asunto es que incluso cuando los misioneros se apropiaron de las prácticas indígenas para penetrar más profundamente con su Evangelio, el producto de esa ecuación es una hibridez producida por múltiples procesos de analogía, comparación y similitud que, originariamente, no se encontraba en las intenciones de los conquistadores o misioneros. Sin embargo, a pesar de que esta línea de reflexión es interesantísima, lo que nos interesa rescatar aquí es el producto que sí buscaban obtener los misioneros, la conquista espiritual, y uno de los mecanismos escénicos que utilizaron para lograrlo, la prefiguración de la derrota.

Ahora bien, en términos de antecedentes no sólo debemos mencionar los europeos, sino también los indígenas. Creemos que las raíces de este fenómeno prefigurativo, tanto a nivel indígena como español, se remontan a épocas previas a la conquista. Sabemos gracias a los cronistas que una de las tantas maneras en que los indígenas articulaban un mecanismo semejante en sus rituales, trascendiendo de lo dramático a lo real, sucedía específicamente cuando éstos terminaban en sacrificios humanos, como lo indica Kozinska (1992:103):

los dioses necesitaban la sangre de sus súbditos para asegurar la continuidad del universo. Muchas danzas que empezaban ingenuamente como una simple escaramuza fingida terminaban con una ceremonia sangrienta. Así describía Bernardino de Sahagún una parte de la fiesta dedicada a Huitzilopochtli:

[...] detrás de todos iban los cuatro: dos tigres y dos águilas que eran hombres fuertes; iban haciendo ademanes de pelea con la espada y con la rodela como quien esgrime y en llegando abajo iban hacia donde estaba la piedra como muela donde acuchillaban a los cautivos. (101)

En lo que respecta a las teatralidades prehispánicas, tenemos noticias de ellas, por ejemplo, a través de las cartas de Cortés, quien reconoce haber visto en Tenochtitlán "Uno como teatro, que está en medio de ella [...] de altura de dos estados y medio, y de esquina a esquina habrá treinta pasos; el cual tenían ellos para cuando hacían algunas fiestas y juegos, que los representadores de ellos se ponían allí porque toda la gente del mercado y los que estaban en bajo y encima de los portales pudiesen ver lo que se hacía" (Horcasitas, 2004: 112). 
O el teatro que se encontraba en el templo de Quetzalcoatl según la descripción del códice Ramírez:

Tenía un patio mediano, donde el día de su fiesta, se hacían grandes bailes, regocijos y muy graciosos entremeses, para lo cual había en medio de este patio un pequeño teatro de a treinta pies en cuadro, curiosamente encalado, el cual enramaban y aderezaban para aquel día con toda la pulicie posible, cercándolo todo de arcos hechos de toda diversidad de rosas y plumería, colgando a trechos muchos pájaros y conejos y otras cosas apacibles, donde después de haber comido se juntaba toda la gente, y salían los representantes y hacían entremeses, fingiéndose sordos, arromadizos, cojos, ciegos y mancos, viniendo a pedir sanidad al ídolo, los sordos respondiéndole adefesios, y los arromadizos tosiendo y sonándose [...] lo cual concluido, haciendo un gran mitote o fiesta con todos estos personajes, se concluía la fiesta. (Arrom, 1956: 16-17)

Por otra parte, los españoles llegados a América aún eran parte de un sistema medieval en los términos que Le Goff (1977) señala cuando establece que la cultura eclesiástica actuaba frecuentemente tratando de impedir la cultura folklórica mediante la represión, aunque, por otro lado, requería de una constante actualización de conocimientos en esta última para poder penetrar en el pueblo. Así, el sentido predilecto que fue utilizado por los misioneros para llegar al pueblo americano fue la vista. Bajo esta perspectiva los franciscanos llenaron el año no solo de representaciones teatrales, rituales y todo tipo de performances, sino que también plasmaron por doquier imágenes religiosas. Las teatralidades más didácticas y explícitas fueron los misterios, donde se escenificaban pasajes de la Biblia o hagiografías. Si recapitulamos, entre las fiestas asociadas al Corpus, más las patronales y las de las festividades cristianas por excelencia (Semana Santa, Navidad, etc.), el año se llenaba de festividades que recalcaban una y otra vez elementos de la vida cristiana.

La ciudad vivía con la ilusión del próximo festejo. En las plazas públicas o en frente de las iglesias, lugares donde podía caber mucha gente, se construían grandes tablados, a veces compuestos de varios pisos para que el Cielo, la Tierra y el Infierno fueran más naturales. Una sofisticada maquinaria teatral servía para representar las escenas de una manera 
más verdadera y fidedigna posible. Todo el sistema de [...] volerie permitía al actor de la Ascención de Cristo subir milagrosamente al cielo o a los condenados del Juicio Final desaparecer bruscamente en las llamas del infierno. (Kozinska, 1992:102)

Como último vínculo entre la tradición medieval y el concepto de prefiguración en la Conquista, es rescatable la apreciación de Kozinska cuando señala que en la imaginación medieval no existían límites exactos entre lo ficticio y lo real -de lo cual hemos señalado abundantes muestras en las citas anteriores- "los personajes bíblicos se convertían en seres de carne y hueso, encarnándose en los actores de misterios y así permanecían clavados en la memoria del público. El cristianismo medieval, pues, era una religión encarnada dentro de un espacio festivo ritual" (1992: 104).

\section{Palabras de cierre}

A lo largo de estas páginas hemos querido dar cuenta de parte de un complejo proceso colonial que es perceptible a través de distintas crónicas del siglo XVI que rescatan las representaciones escénicas que tuvieron lugar en Nueva España. Tanto los textos como el objeto descrito nos permiten reconstituir un entramado contextual que da cuenta de diversos factores que concomitaban en estas expresiones.

Por un lado, el acervo medieval de los conquistadores y misioneros franciscanos estuvo plasmado en la mayoría de las representaciones teatrales, específicamente en las de moros y cristianos. Las teatralizaciones de estas batallas, de antigua tradición en la Península, permitieron no solo la articulación de nuevos discursos nacidos de la coyuntura conquistadora, sino también la reactualización de discursos políticos e ideológicos medievales.

Por otra parte, los mismos indígenas americanos tenían una amplia tradición teatral donde también es posible encontrar, por ejemplo en las víctimas sacrificiales, técnicas dramáticas similares a la prefiguración aunque éstas están profundamente imbuidas en el aspecto ritual de las culturas de las cuales son parte, hecho que diferencia ambas tradiciones escénicas. 
Cabe señalar que en el aspecto estructural de las representaciones de moros y cristianos, de las cuales la Conquista de Jerusalén es parte, presentan una variabilidad de motivos que permite su fácil adaptación a nuevos escenarios históricos, políticos e ideológicos, lo que explica parcialmente su amplia difusión y arraigo en la tradición americana, donde ha pasado a formar parte del folclor de ciertas naciones.

Ahora bien, en términos específicos, creemos que los datos proporcionados por las fuentes estudiadas permiten concluir que las escenificaciones de moros y cristianos no fueron, en un primer momento, producidas en cualquier ciudad o región, sino que más bien la elección del emplazamiento respondía a una serie estratégica de factores económicos, políticos, históricos y religiosos.

En la Conquista de Jerusalén hemos podido apreciar, junto con la prefiguración, otros mecanismos que, al menos colonialmente, constantemente relacionaban dramáticamente ámbitos de la vida real con el carácter ficcional de las mismas representaciones. La textualidad que construyó fray Toribio Benavente a través del recurso de las cartas es, como lo señalamos más arriba, una instancia donde se recapitula y se enfatiza lo recientemente acontecido en los tablados, sino que además llevaba del plano de la realidad al ficcional a los espectadores, contribuyendo a la instauración de un discurso de la victoria, por parte de los españoles, y de la derrota espiritual, por parte de los indígenas.

La apropiada lectura del discurso vencedor se basaba no solo en la representación misma de la Conquista de Jerusalén, sino en dos escenificaciones previas, en espacios geográficos distintos pero que en conjunto permiten establecer una lectura única de este proceso. Nos referimos a La batalla de los naturales y a la Conquista de Rodas.

Quisiéramos finalizar esta breve reflexión con las palabras de Fernando Horcasitas para quien "los misioneros dieron forma articulada a sus esperanzas en los simulacros de México (Rodas) y Tlaxcala (Jerusalén). Unidos europeos e indígenas bajo el Papa, el emperador y el virrey, y derrotado el enemigo, comenzaría para todos una nueva y utópica era" (2004: 612). 


\section{Bibliografía}

Acosta, Vladimir (1996). La humanidad prodigiosa. El imaginario antropológico medieval. Tomo I y II. Venezuela: Monte Ávila editores.

Adorno, Rolena (1992). "Los debates sobre la naturaleza del indio en el siglo XVI, textos y contextos". Revista de estudios hispánicos 9. Adorno 47-66.

Álvarez Moctezuma, Isabel (2008). "La cultura musical en los ámbitos indígenas de la Nueva España". Revista Arqueología Mexicana XVI/94, 47-51.

Aracil, María Beatriz. "Teatro e ideología en el siglo XVI novohispano". En: El teatro mexicano visto desde Europa: Actes des 1res Journées Internationales sur le Théâtre Mexicain. En <http:/ / www.cervantesvirtual.com/ servlet/ SirveObras/12252744220140495543435/p0000001. htm\#9>

Aracil, María Beatriz (2008). "Teatro evangelizador y poder colonial en México". Revista Destiempos año 3/14, 220-234.

Arias, Ricardo (1970). El concepto de destino en la literatura española medieval. Madrid: Editorial Ínsula.

Arrom, José (1956). Historia del teatro hispanoamericano. Época colonial. La Habana: Anuario Bibliográfico Cubano.

Benavente, Toribio de. Historia de los indios de Nueva España. Colección de documentos para la historia de México. Tomo primero. Joaquín García Izcalbaceta, editor. En <http: / / www.cervantesvirtual.com/ servlet/Sirve Obras / 68048408217915506322202/index.htm>

Benavente, Toribio de (1985). Historia de los indios de Nueva España. Georges Baudot editor. Madrid: Clásicos Castalia.

Beutler, Gisela. "Algunas observaciones sobre los textos de moros y cristianos en México y Centroamérica". Centro virtual Cervantes. En <http://cvc.cervantes.es/ obref/aih/pdf/08/aih_08_1_024.pdf> 
Brisset Martín, Demetrio (1993). "Clasificación de los moros y cristianos". Gazeta de Antropología 10. En <http://www.ugr. es / pwlac/G10_12DemetrioE_Brisset_Martin. html>

Cáceres, Milena (2005). La fiesta de moros y cristianos en el Perú. Lima: PUC.

Chavero, Alfredo (1979). El lienzo de Tlaxcala. México: Editorial Cosmos.

Díaz del Castillo, Bernal (1980a). Historia verdadera de la conquista de la Nueva España. México: Porrúa.

(2005b). Historia verdadera de la conquista de la Nueva España. México: UNAM.

Domínguez García, Javier (2008). De apóstol matamoros a Yllapa mataindios. Salamanca: Ediciones Universidad de Salamanca.

Enríquez, Lucero (2008). "La música en la Nueva España". Revista Arqueología Mexicana. XVI/94, 52-59.

García-Verdugo, Marisa (2008). "La tradición teatral popular en la América colonial: moros y cristianos en Chiquimula, Huamantanga y Chimayó. Revista Tejuelo 3, 89-101.

Gibson, Charles (1991). Tlaxcala en el siglo XVI. Tlaxcala: Gobierno del Estado de Tlaxcala.

Goff, Jacques le (1977). Pour un autre Moyen Age. Temps, travail et culture en Occident: 18 essais. París: Gallimard.

Gruzinski, Serge (1991). La colonización de lo imaginario. México: F.C.E.

Horcasitas, Fernando (2004). Teatro náhuatl. México: UNAM.

Kozinska, Joanna (1992). "La representación encarnada: una reflexión sobre el teatro evangelizador en Nueva España". Discurso colonial hispanoamericano. Sonia Rose de Fuggle, coordinadora. Amsterdam: Rodopi, 101-115.

Matos Moctezuma, Eduardo (2008). "Las danzas de moros y cristianos y de la conquista". Revista Arqueología Mexicana XVI/94, 60-65. 
Medina, José Ramón (1992). Historia real y fantástica del nuevo mundo. Venezuela: Biblioteca Ayacucho.

Monterde, Francisco (1925). Bibliografía del teatro en México. México: Monografías bibliográficas mexicanas.

Quiñones Melgoza, José (1995). Teatro mexicano. Historia y dramaturgia. Vol. III y IV. México: Consejo nacional para la cultura y las artes.

Ramírez Sierra, Hugo Hernán (2009). Fiesta, espectáculo y teatralidad en el México de los conquistadores. Frankfurt: Iberoamericana.

Ricard, Robert (1932). "Contribution á l'étude des fêtes de moros y cristianos au Mexique". Journal de la Société de américanistes 24/1, 51-84.

Ricard, Robert (1986). La conquista espiritual de México. México: FCE.

Rivera, Octavio (2008). "Fiestas por los Austrias en la Ciudad de México, siglo XVI". Revista Destiempos 14, Año 3, 250-261.

Toro, Alfonso de (2006). "Escenificaciones de la hibridez en el discurso de la conquista. Analogía y comparación como estrategias translatológicas para la construcción de la otredad". Atenea 493, 87-149.

Weckmann, Luis (1984). La herencia medieval de México. México: El Colegio de México. 